\title{
Bronchopulmonary Sequestration Presenting as a Spontaneous Pneumothorax
}

\author{
Daniel JP Coutinho MD, Margarida CP Dias MD, Maria J Oliveira MD, Daniel CS Vaz MD, \\ and Maria T Shiang MD
}

\begin{abstract}
Introduction
Bronchopulmonary sequestration is a relatively rare medical condition wherein a mass of nonfunctioning primitive lung tissue does not communicate with the tracheobronchial tree and receives its blood supply from an anomalous systemic artery. ${ }^{1-6}$ It usually manifests at younger ages and is rare in adults. Its clinical presentation varies in adulthood. ${ }^{1-3}$ We report the case of a young male adult who was diagnosed with recurrent pneumothorax, the initial clinical manifestation of an intralobar bronchopulmonary sequestration. A brief review of clinical features, diagnostic strategies, and management options (with a focus on intralobar sequestration) of this case follows.
\end{abstract}

\section{Case Summary}

An 18-y-old male presented with acute-onset chest pain in the left hemithorax and dyspnea. He was a nonsmoking student and football referee with no history of recent trauma, illegal drug use, or maintenance medication. His past medical history was significant for constitutional growth delay during childhood and a recent hospitalization for a left spontaneous pneumothorax, which was treated with a chest drain. There was no history of any other previous pulmonary disease.

His chest radiograph revealed a left marginal pneumothorax (Fig. 1). Due to the pneumothorax dimensions, conservative treatment was adopted. Because this was his

\footnotetext{
All authors are affiliated with the Pulmonology Department, Centro Hospitalar de Vila Nova de Gaia e Espinho, Vila Nova de Gaia, Portugal.

The authors have disclosed no conflicts of interest.

Correspondence: Daniel JP Coutinho MD, Serviço de Pneumologia, Centro Hospitalar de Vila Nova de Gaia e Espinho, Rua Conceição Fernandes, 4434-502 Vila Nova de Gaia, Portugal. E-mail: dpcoutinho@gmail.com.
}

DOI: $10.4187 /$ respcare.03104

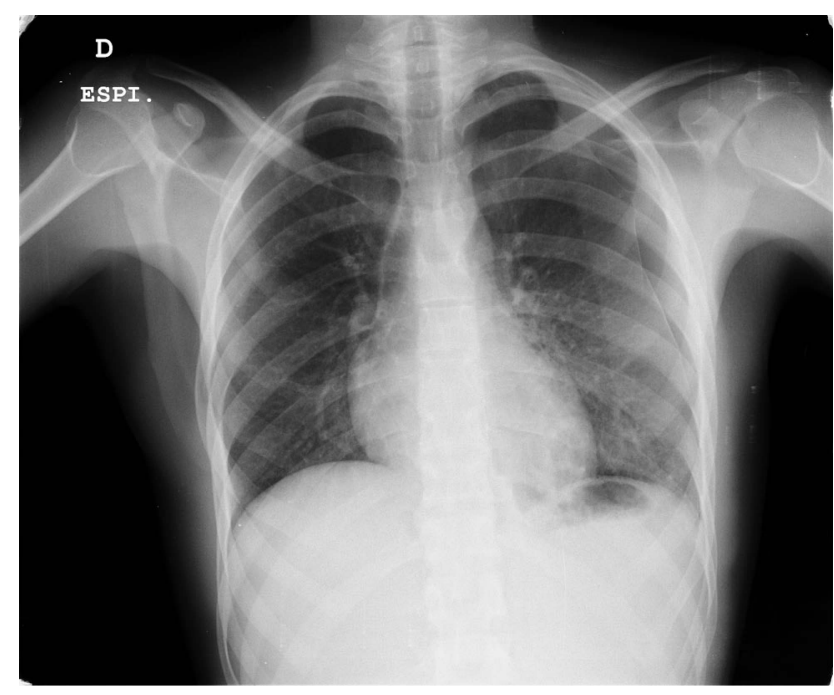

Fig. 1. Marginal left pneumothorax.

second pneumothorax, a computed tomography (CT) angiography of the chest was ordered (the results from a previous $\mathrm{CT}$ scan indicated the need for $\mathrm{CT}$ angiography to clarify previous findings of an abnormal vascular structure). CT angiography showed a hypodense area in the posteroinferior segment of the lower left lobe with ectatic bronchial structures, no communication with the tracheobronchial tree, and a small cystic lesion $(12 \mathrm{~mm})$. It also revealed an anomalous blood vessel from the descending aorta in the thoracoabdominal transition, supplying the abnormal segment described and regular venous drainage through the pulmonary veins. There was no evidence of subpleural blebs (Fig. 2). Furthermore, fiberoptic bronchoscopy showed no structural abnormalities, and a ventilationperfusion defect in the lower left lobe was detected by a quantitative ventilation-perfusion lung scan.

These findings were consistent with bronchopulmonary sequestration. The patient underwent left thoracotomy and left lower lobe resection. The arterial branch from the aorta was successfully isolated and ligated, and the lesion was removed without any incident. No evidence of pleural blebs was found during the surgery, and pathology of the 

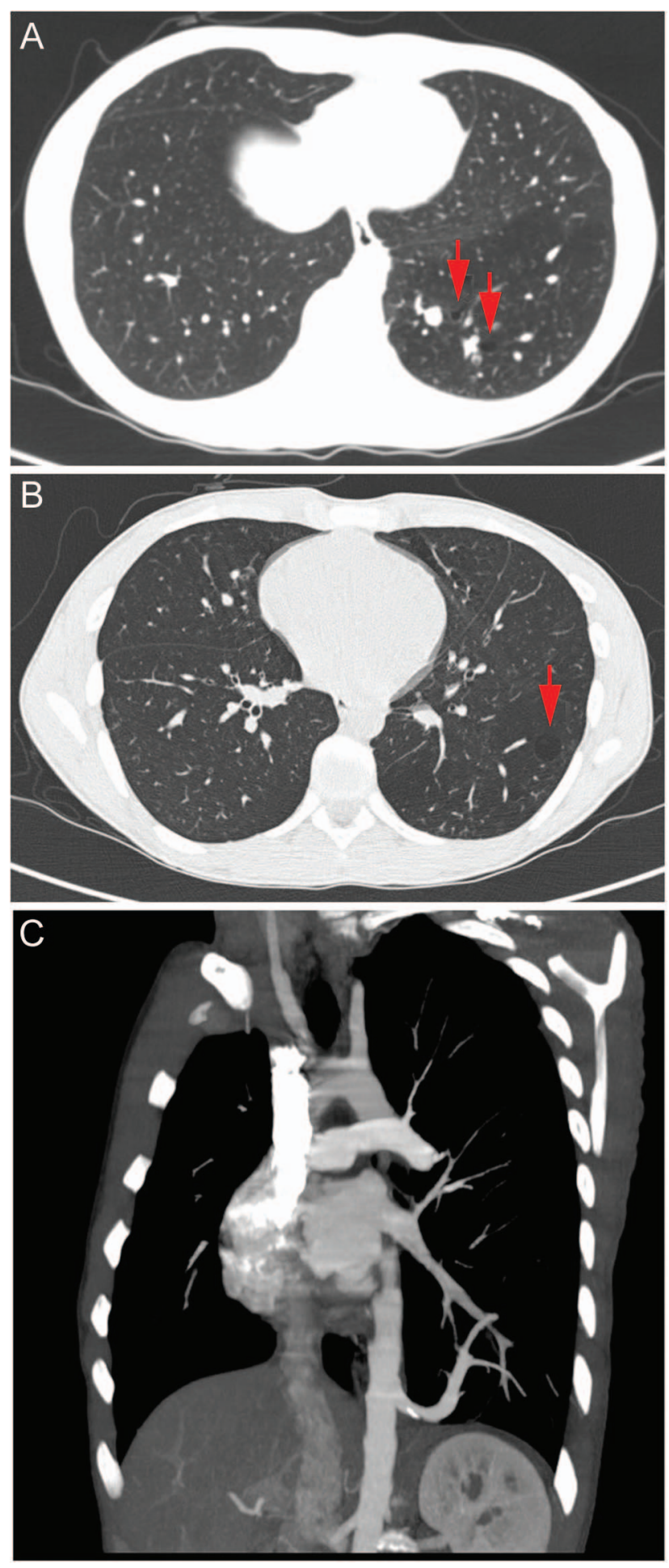

Fig. 2. Computed tomography showing a hypodense area in the posteroinferior segment of the lower left lobe with some ectatic bronchial structures (A, arrows), a small cystic lesion (B, arrow), and an anomalous supplying blood vessel from the descending aorta (C).

resected specimen confirmed the diagnosis of intralobar sequestration, showing extensive areas of inflammatory lung parenchyma with small cystic spaces. After surgery, the patient had an uneventful recovery.

\section{Discussion}

Bronchopulmonary sequestration was first reported by Huber in 1777, and the term sequestration was first introduced by Pryce in $1946 .^{1,4,7}$ It is a relatively rare entity, comprising $0.15-6.45 \%$ of all pulmonary malformations. , $^{1,4,6}$ Bronchopulmonary sequestration is diagnosed in the first 2 decades of life in $\sim 60 \%$ of cases. ${ }^{4-6}$

Bronchopulmonary sequestration can be classified as intralobar or extralobar sequestration. Intralobar sequestration is the most common form ( $\sim 75 \%$ of cases) and develops in normal lung tissue without its own visceral pleura. Extralobar sequestration is a true accessory lung, with its own pleural envelope. ${ }^{4-6}$ Several theories about bronchopulmonary sequestration etiology have been proposed, ${ }^{4-6,9}$ and as with any other congenital malformation of the lower respiratory tract, there is an embryological explanation for its origin. This is true for extralobar sequestration, with the widely accepted Pryce's traction theory, where the persistence of systemic arteries causes traction of the lung such that a portion separates from the main lung mass during embryogenesis. However, in intralobar sequestration, it is thought that this lesion might be acquired, along with the development of a systemic arterial supply, as a result of a lung infection. ${ }^{4-6}$ In addition, an association between bronchopulmonary sequestration and abnormal expression of the homeobox gene Hoxb-5 was also described. ${ }^{4}$

Diagnosis of intralobar sequestration usually occurs during late adolescence but may remain unrecognized after the age of 20 , and it is equally distributed between genders. ${ }^{4-8}$ Patients with intralobar sequestration may remain asymptomatic for years. Nevertheless, they can present with an incidental pulmonary lesion on imaging or, more commonly, manifest different degrees of unspecific pulmonary symptoms such as chest pain and wheezing during recurrent respiratory infections. ${ }^{4-6,10}$ The present case refers to a young male adult presenting with a spontaneous pneumothorax due to intralobar sequestration. Because intralobar sequestration lacks normal communication with the airway, it rarely gives rise to a spontaneous pneumothorax, but this can happen when a cyst ruptures eventually, secondary to an infectious process. ${ }^{8,11}$ Other complications such as hemoptysis, hemothorax, and infarction have been described..$^{11}$ Intralobar sequestration is almost always located in the lower lobes $(\sim 60 \%$ in the basal posterior segment of the left lower lobe) and is usually supplied by large-caliber vessels derived from the aorta or one of its branches. ${ }^{6,8}$ Venous drainage is through the pulmonary veins. ${ }^{6,12}$ Intralobar sequestration is rarely located in the upper lobes and is rarely associated with other cardiopulmonary anomalies..$^{5,6,8}$ 
The most useful diagnostic methods for bronchopulmonary sequestration are CT angiography, magnetic resonance angiography, and digital subtraction angiography. Previously, diagnosis always required pulmonary angiography to demonstrate abnormal sequestration; however, in recent years, CT angiography and magnetic resonance angiography have been successfully used as diagnostic tools. - $5,13,14$ Furthermore, ultrasonography/color Doppler can show the artery supplying pulmonary sequestrations that are close to the diaphragm or liver. This method also has the advantage of being noninvasive and safe, making its use ideal in prenatal and postnatal settings, but it has limited value in adults. ${ }^{3,15}$

For evaluation of a sequestered lung and its vascular supply in patients with a chest radiograph suggesting bronchopulmonary sequestration, $\mathrm{CT}$ angiography is the diagnostic imaging method of choice. ${ }^{4,14} \mathrm{CT}$ can help in diagnosing other lung conditions that may mimic sequestration on a chest radiograph. ${ }^{4,14}$ Although magnetic resonance angiography may be useful in selected cases when CT is contraindicated (with hypersensitivity to iodinated contrast media or when exposure to radiation is undesirable), the evaluation of lung parenchyma with this technique is suboptimal. ${ }^{3,4,14}$ Finally, digital subtraction angiography is reserved for those cases in which the clinical and radiological suspicion for sequestration is high but a supplying systemic vessel cannot be shown using CT angiography or magnetic resonance angiography. 3,4,14

Treatment of bronchopulmonary sequestration depends on whether the patient is symptomatic or not. Surgical resection is recommended in all symptomatic patients, but it is a controversial choice of treatment for asymptomatic patients. ${ }^{1,5}$ However, in asymptomatic patients with intralobar sequestration, elective resection is usually recommended due to a potentially high rate of complications. ${ }^{1,4,5}$ For these patients, lobectomy is often the treatment of choice, whereas resection of the sequestered segment alone is not usually recommended due to possible surgical complications caused by intersegmental plane destruction by previous inflammatory processes. ${ }^{1,5}$ In recent years, videoassisted thoracoscopic surgery has been used as an alternative to conventional thoracotomy in selected patients. ${ }^{4,8}$

\section{Teaching Points}

- Spontaneous pneumothorax can be the initial clinical manifestation of an intralobar sequestration. Physicians should be aware of this rare congenital condition, which can present in adults with symptoms of common diseases such as recurrent respiratory infections or, as in this case, a spontaneous pneumothorax.

- In intralobar sequestration, a spontaneous pneumothorax might occur due to a rupture of a cyst. Other complica- tions such as hemoptysis, hemothorax, and infarction have been described.

- CT angiography is the diagnostic imaging method of choice for evaluation of intralobar sequestration and its vascular supply. Magnetic resonance angiography, digital subtraction angiography, and ultrasonography/color Doppler may be useful in selected cases.

- Surgical resection is recommended in all symptomatic patients with intralobar sequestration and is also usually recommended in asymptomatic patients due to a potentially high rate of complications. Lobectomy (via conventional thoracotomy/video-assisted thoracoscopic surgery) is the treatment of choice.

\section{REFERENCES}

1. Van Raemdonck D, De Boeck K, Devlieger H, Demedts M, Moerman P, Coosemans W, et al. Pulmonary sequestration: a comparison between pediatric and adult patients. Eur J Cardiothorac Surg 2001;19(4):388-395.

2. Aryal G, Pathak V. Bronchopulmonary sequestration presenting as recurrent pneumonia. WMJ 2011;110(5):240-242.

3. Wei Y, Li F. Pulmonary sequestration: a retrospective analysis of 2625 cases in China. Eur J Cardiothorac Surg 2011;40(1):e39-e42.

4. Lin CH, Chuang CY, Hsia JY, Lee MC, Shai SE, Yang SS, Hsu CP. Pulmonary sequestration-differences in diagnosis and treatment in a single institution. J Chin Med Assoc 2013;76(7):385-389.

5. Vieira J, Rego A, Oliveira A, Sá Ferreira D, Furtado A, Couceiro A, et al. Bronchopulmonary sequestration-a 12-year experienc. Rev Port Pneumol 2006;12(5):489-501. Article in English, Portuguese.

6. Halkic N, Cuénoud PF, Corthésy ME, Ksontini R, Boumghar M. Pulmonary sequestration: a review of 26 cases. Eur J Cardiothorac Surg 1998;14(2):127-133.

7. Furukawa S, Takaya A, Nakagawa T, Sakaguchi I, Nishi K. Extralobar pulmonary sequestration: an autopsy case. Rom J Leg Med 2010;18:179-182.

8. Spyratos D, Kalpakidis V, Giouleka P, Chloros D, Sichletidis L. An unusual cause of spontaneous pneumothorax. BMJ Case Rep 2011; doi:10.1136/bcr.08.2010.3209.

9. Savic B, Birtel FJ, Tholen W, Funke HD, Knoche R. Lung separation: report of seven cases and review of 540 published cases. Thorax 1979;34(1):96-101.

10. Pugliese JG, Bártholo TP, Santos HT, Saito EH, Costa CH, Rufino $R$. Usefulness of chest $\mathrm{CT}$ in the diagnosis of pulmonary sequestration. J Bras Pneumol 2010;36(2):260-264.

11. Laberge JM, Puligandla P, Flageole H. Asymptomatic congenital lung malformations. Semin Pediatr Surg 2005;14(1):16-33.

12. Yamamura Y, Hida Y, Kaga K, Kawada M, Niizeki H, Ichinokawa M, Kondo S. Simultaneous resection of bilateral intralobar and extralobar pulmonary sequestrations with video-assisted thoracoscopic surgery. Ann Thorac Surg 2009;87(6):1939-1941.

13. Fontalba Navas M, Sánchez Gil J, Calvo Bonachera J. Bilateral pulmonary sequestration in an adult: case report and review of the literature. Arch Bronconeumol 2013;49(9):410-411. Article in English, Spanish.

14. Abbey P, Das CJ, Pangtey GS, Seith A, Dutta R, Kumar A. Imaging in bronchopulmonary sequestration. J Med Imaging Radiat Oncol 2009;53(1):22-31.

15. Dhingsa R, Coakley FV, Albanese CT, Filly RA, Goldstein R. Prenatal sonography and MR imaging of pulmonary sequestration. AJR 2003;180(2):433-437. 